\title{
Title
}

\section{Maturation-dependent vulnerability of emotion regulation as a response to COVID-19 related stress in adolescents}

\section{Authors}

Patrícia Gerván ${ }^{\mathrm{a}, \mathrm{b}, *}$, Nóra Bunford ${ }^{\mathrm{c}}$, Katinka Utczás ${ }^{\mathrm{d}}$, Zsófia Tróznaid ${ }^{\mathrm{d}}$ Gyöngyi Oláh ${ }^{\mathrm{b}, \mathrm{e}, \mathrm{f}}$, Hanna Szakács ${ }^{\mathrm{e}, \mathrm{f}}$, Ferenc Gombos ${ }^{\mathrm{b}, \mathrm{f}}$ \& Ilona Kovács ${ }^{\mathrm{b}, \mathrm{c}, \mathrm{f}}$

\footnotetext{
a Institute of Psychology, Pázmány Péter Catholic University, Budapest, 1088, Hungary

b Adolescent Development Research Group, Hungarian Academy of Sciences - Pázmány Péter Catholic University, Budapest, 1088 Hungary

${ }^{\mathrm{c}}$ Institute of Cognitive Neuroscience and Psychology, Res. Centre for Natural Sciences, Budapest, 1117 Hungary

${ }^{\mathrm{d}}$ Research Centre for Sport Physiology, University of Physical Education, Budapest, 1123 Hungary

${ }^{\mathrm{e}}$ Doctoral School of Mental Health Sciences, Semmelweis University, Budapest, 1089 Hungary

${ }^{\mathrm{f}}$ Laboratory for Psychological Research, Pázmány Péter Catholic University, Budapest, 1088 Hungary
}

* corresponding author: Patrícia Gerván, Institute of Psychology, Pázmány Péter Catholic University, 1 Mikszáth sq., Budapest, 1088 Hungary, e-mail:gervan.patricia@ btk.ppke.hu

\section{Acknowledgements}

Funding: This work was supported by the National Research, Development and Innovation Office of Hungary (Grant K-134370, 2020) to I.K., and by the Eötvös Loránd Research Network, Hungary (ELRN-PPCU Adolescent Development Research Group). 


\section{Abstract}

Background: The COVID-19 pandemic created highly unpredictable circumstances which resulted in increased levels of psychological strain. Here we investigate pandemic-related alterations in emotion regulation in adolescents assessed before and during the pandemic. We also take biological age into account in the response to the pandemic.

Methods: We compared baseline data on the Difficulties in Emotion Regulation Scale (DERS) total scores of a pre-pandemic adolescent cohort $(n=241)$ with those obtained during the second wave of the pandemic $(n=266)$. We estimated biological age based on an ultrasonic boneage assessment procedure in a subgroup of males. We included both grammar school and vocational school students in the $9^{\text {th }}$ and $10^{\text {th }}$ grades and analyzed their data independently.

Findings: There is a gender difference in the timing of vulnerability for pandemic-related stress in grammar school students: females are affected a year earlier than males. Vocational school male students mature faster than grammar school male students, and the timing of emotional vulnerability also precedes that of the grammar school students.

Discussion: We interpret our findings in a developmental model suggesting that there might be a window of highest vulnerability in adolescent emotion regulation. The timing of the window is determined by both chronological and biological age, and it seems to be different for females and males.

Application to Practice: Defining the exact temporal windows of vulnerability for different adolescent cohorts allows for the timely integration of preventive actions into adolescent care to protect mental health during future chronic stressful situations.

\section{Keywords:}

COVID-19, adolescence, emotion regulation, DERS, pubertal maturation, boneage

\section{Highlights:}

- Emotion regulation is compared across pre-pandemic and pandemic cohorts of adolescents.

- Females show an earlier window of stress-related vulnerability than males.

- Advanced maturity in vocational school males as assessed by boneage estimation.

- Advanced maturation moves the vulnerability window to an earlier time. 


\section{Introduction}

Adolescents have been facing multiple hardships because of the COVID-19 pandemic: with schools closed, their daily routines are disrupted; social distancing and other containment measures increase the prevalence of depressive and anxiety symptoms (Zhou et al., 2020, Ellis et al., 2020); adjustment to the 'outside world' once the lockdown is lifted is a challenge for some students, especially for those with mental health problems (Lee, 2020). Under these extreme circumstances, the acquisition of age-appropriate emotion regulatory skills becomes one of the most important developmental tasks, and the maturity of the emotion processing brain circuitry in the background seems to be a particularly relevant aspect of healthy functioning.

Under regular circumstances, by the time youth reach adolescence, they have acquired differentiated and diversified emotion expression and regulation skills and are able to incorporate environmental feedback and accordingly modify their emotional expressions and regulatory responses (Bunford \& Evans, 2017). On the other hand, fully adult-like emotion regulation cannot be expected since the biological changes of adolescence involve brain structures and systems implicated in emotion expression and regulation as well. There is, for example, a second surge of synaptogenesis (dendritic pruning and myelinogenesis), making the teenage years one of the most dynamic periods of human development (Arain et al., 2013). Due to the considerable increases in sex hormones, neurocircuitry is still functionally and structurally unstable resulting in marked vulnerability (Arain et al., 2013). A significant portion of brain development and growth in adolescence is the construction and strengthening of regional neurocircuitry and pathways, manifesting as active maturation of e.g., the basal ganglia and the frontal lobe (Arain et al., 2013), with both the basal ganglia (Johnson et al., 2003) and the frontolimbic system (Banks et al., 2007) implicated in emotion generation and regulation. The prefrontal cortex remains under construction and there is a decrease in dopamine and serotonin levels (Arain et al., 2013), with these neurotransmitters also involved in emotion regulation (GABA: Thayer \& Lane, 2000; dopamine: Laviolette, 2007; serotonin transporter gene: Canli \& Lesch, 2007).

Moderated by age and context, there are gender differences in emotion regulation. females employ both more adaptive (e.g., active coping and re-evaluation) and maladaptive (e.g., rumination and suppression) emotion regulatory strategies relative to males (Chaplin \& Aldao, 2013), with this difference potentially reflecting the more general tendency of women being more aware of their emotions and more open to engaging with their emotions (Nolen-Hoeksema et al., 1999). females tend to show better emotion regulation in young adolescence (age 9-12 years) but worse emotion regulation than males in middle adolescence (age 13-16 years,(Zimmer-Gembeck \& Skinner, 2011), highlighting a stage of increased emotional vulnerability for females during the middle adolescent years as also reflected in the frequency of anxiety-depressive problems during this developmental period (Muris et al., 2000) 
There is a relative paucity of empirical research on the direct effect of acute, laboratory-induced stress on emotion regulation in children and adolescents (Langer et al., 2020), and the available data are mixed, with some evidence indicating acute stress impairs emotion regulation (Raio et al., 2013; Raio \& Phelps, 2015) and other findings suggesting improvements in emotion regulation (Kinner et al., 2014; Langer et al., 2020). Regarding the effects of acute, non-laboratory induced stress, findings on child and adolescent survivors of disasters, wars, and other acute events are also inconsistent regarding behavioral and emotional outcomes. Some data indicate an increase in behavioral (e.g., aggression) and emotional (e.g., anxiety, depression) problems (Marsee, 2008; Scott et al., 2013) whereas others show no adverse effects on these outcomes (Durkin et al., 1993).

Our purpose was to see how the current pandemic events impact emotion regulation in adolescents. In addition to assuming a gender difference in the timing of the strongest impact, we were interested in those potential windows of vulnerability that are suggested by the abovementioned brain maturational processes (e.g., pruning, late frontolimbic maturation, neurotransmitter imbalance). To allow for all participants of this study to reach adolescence (Farello et al., 2019), we focused on a cohort of students in the $9^{\text {th }}$ and $10^{\text {th }}$ grades. The reason to rely on grades instead of chronological age was that we attempted to study groups of students who entered school at about the same level of school readiness, therefore their cognitive maturity was at about a similar level. In addition to age, we were also interested in contextual effects that might have an impact on maturation, therefore, we included both grammar school and vocational school students. And finally, on a subgroup of students, we employed bone age measurements to assess their biological maturity levels and to see how biological age might be associated with emotion regulation development. A unique characteristic of our study is that we compare pre-pandemic and pandemic emotion regulation results within age-groups and genders.

\section{Methods}

\section{Participants}

To study the impact of the COVID-19 pandemic on emotion regulation of adolescents, we compared a Pre-Pandemic and a Pandemic cohort. Both cohorts included students from grammar schools attending 9th or 10th grade and vocational schools attending 9th grade. Descriptive statistics of the Pre-Pandemic and Pandemic cohort are summarised in Table 1. in the Results section.

The Pre-Pandemic grammar school cohort consisted of 170 students. In the $9^{\text {th }}$ grade, 63 females (age $=14.82 \mathrm{y}, \mathrm{SD}=0.49$ ) and 22 males (age=14.94y, $\mathrm{SD}=0.65)$ participated, in the $10^{\text {th }}$ grade, 58 females (age=15.76y, $\mathrm{SD}=0.43$ ) and 27 males ( age=15.96y, SD=0.43) took part. In the Pandemic grammar school cohort, there were 208 respondents. In the $9^{\text {th }}$ grade, 59 females $($ age $=15.16 y$, 
$\mathrm{SD}=0.35$ ) and 53 males (age $=15.39 \mathrm{y}, \mathrm{SD}=0.42$ ) participated. In the $10^{\text {th }}$ grade, 53 females (age $=16.16 \mathrm{y}, \mathrm{SD}=0.44$ ) and 43 males (age $=16.55 \mathrm{y}, \mathrm{SD}=0.45)$ took part.

In the Pre-Pandemic cohort of $9^{\text {th }}$ grader vocational school males, 71 students participated (age=15.49y, $\mathrm{SD}=0.55$ ). Data were gathered from 58 (age $=15.47 \mathrm{y}, \mathrm{SD}=0.45$ ) participants in the Pandemic sample.

All the vocational school participants attended the BGSZC Bánki Donát Vocational High School of Transport Engineering where the proportion of female students is less than $1 \%$. Due to the low proportion of females, we did not have the opportunity to collect an adequate amount of data among them. When describing our vocational school population, it is important to note that the economic, social, and cultural background differs significantly from that of the grammar school population described above. Typically, these students could be characterized with a lower socio-economic background as compared to grammar school students.

127 males took part in boneage assessments: 31 students attended grammar schools (age $=15.3 \mathrm{y}$, $\mathrm{SD}=0.46$ ) and 96 students attended a vocational school (age $=15.4 \mathrm{y}, \mathrm{SD}=0.57$ ). Participants from both school types were $9^{\text {th }}$ grade students.

\section{Tools}

\section{Questionnaire}

Emotion regulation processes were measured by the validated Hungarian version (Kökönyei et al., 2014) of Difficulties in Emotion Regulation Scale (DERS; Gratz \& Roemer, 2004). The DERS is a comprehensive, 36-item, self-report measure that assesses the typical levels of emotion dysregulation overall and across the following dimensions: (1) nonacceptance of emotional responses, (2) difficulties engaging in goal-directed behaviours when distressed, (3) difficulties controlling impulsive behaviours, (4) lack of emotional awareness, (5) limited access to emotion regulation strategies perceived as effective, (6) lack of emotional clarity. The DERS has been shown to be correlated with psychological problems reflecting emotion dysregulation, specifically depression, anxiety, suicidal ideation, eating disorders, alcohol and drug use, ADHD, and social impairment (Bunford et al., 2015, 2018; Weinberg \& Klonsky, 2009). It has been validated with adolescents (11-17 years of age) and presented good internal consistency (Bunford et al., 2015; Neumann et al., 2010).

\section{Bone age assessment}

Skeletal maturity (bone age) was assessed with an ultrasonic device (Sunlight BonAge, Sunlight Medical Ltd, Tel Aviv, Israel). All the bone age (BA) measurements were performed on the left 
hand and wrist region of the subjects. The same experimenter performed all the bone age assessments with the same device. The device estimates bone age (in years and months) by measuring the speed of sound and the distance between the transducers, using algorithms based on gender and ethnicity. (See the detailed description of the method in Kovács et al., 2021).

\section{Procedure}

\section{Administering the DERS}

The Pre-Pandemic data of the grammar school sample was obtained from two Hungarian adolescent studies. DERS data was partially provided by Pálma Kriston (Kriston and Pikó, 2018), these data were collected in 2016. The other part of the data was collected in 2020 and 2021 in the context of a larger project by 'Lendület' Adolescents Developmental and Translational Neuroscience Research Group. Data collection of the Pandemic cohort was carried out during the second wave of COVID-19 in Hungary when the levels of new coronavirus cases and COVIDrelated deaths were among the highest in Europe. The data collection was conducted between November 2020 and February, 2021. During this time, Hungary implemented strict pandemicrelated restrictions, which included national quarantine with the closure of schools, shops (except for daily essentials), movie theatres, restaurants, and a curfew after 8 p.m. All gatherings were forbidden, private and family events could be held for up to 10 people. Grammar school students were invited to join the study. Our participation invitation letter was sent out by the school psychologist or the teachers of the students via email. Students were offered extra accountable hours in their volunteer work projects (these projects are mandatory in Hungarian secondary schools) for participating in the research. Due to the epidemiological situation and the lockdown, the data were gathered online via the Qualtrics software, Version 2020 (Qualtrics, Provo, UT).

The vocational school males have been participating in a longitudinal investigation of the Adolescent Development Research Group, Hungarian Academy of Sciences - Pázmány Péter Catholic University. The research team recruited participants for the research in collaboration with the school management, and participants could account for their time spent in the research as classwork. The Pre-Pandemic assessment took place in their school building in November 2019. The students in the Pandemic subgroup participated between November 2020 and February 2021 similarly to the grammar school cohort, the data were gathered on the same remote user testing Qualtrics platform.

\section{Measuring skeletal maturation}

Ultrasonic bone age estimations were carried out before (November 2020) and after (April 2021) the lockdowns. The procedure took place either at the respective schools of the participants or at the Research Centre for Sport Physiology at the University of Physical Education, Budapest. Written informed consent was obtained from all subjects and their parents. 
The PPCU Institute of Psychology Committee for Research in Psychology (reference number 2020_30) and the Hungarian United Ethical Review Committee for Research in Psychology (reference number 2017/84) approved the study. The Pre-Pandemic grammar school sample data collection was approved by the National Institute of Pharmacy and Nutrition (OGYÉI/170898/2019)

\section{Results}

\section{Pre-Pandemic vs. Pandemic emotional regulation score}

The distribution of total DERS scores was abnormal (Shapiro-Wilk normality test >.00); therefore, a non-parametric statistical method was used. Mann-Whitney U tests were conducted to determine if the differences between the Pre-Pandemic and Pandemic subgroups regarding the DERS Total Score were significant. The results of the statistical tests are summarized in Table 1.

Interesting patterns emerged when comparing Pre-pandemic and Pandemic DERS total scores in the population of $9^{\text {th }}$ and $10^{\text {th }}$ graders. In the population of $9^{\text {th }}$ graders, the Pandemic subgroup of the Grammar School (GS) females (Mdn=69.53) was characterized by a significantly higher DERS median score than the Pre-Pandemic subgroup ( $M d n=53.98 ; U=1385, z=-2.42, p=0.015)$. In contrast, we found no significant difference in the medians of total DERS scores between the Pandemic $(M d n=37.58)$ and Pre-Pandemic $(M d n=39)$ subgroups of GS males. In the $9^{\text {th }}$ grader Vocational School (VS) males group the arrangement of DERS total score was similar to that we found in the GS females population: the Pandemic subgroup's median(84.09) also increased as compared to the Pre-Pandemic subgroup's median ( $M d n=49.4 ; U=951.5, z=-5.24, p<0.001)$.

The reverse of the above-described pattern occurred in the population of $10^{\text {th }}$ graders. As for the group of GS females, the Pandemic subgroup ( $\mathrm{Mdn}=55.42)$ showed no significant change in the medians of the total DERS scores as compared to the Pre-pandemic subgroup $(\mathrm{Mdn}=56.54)$. In contrast, the $10^{\text {th }}$ grader GS males Pandemic subgroup showed a significant increment in total DERS score median (39.69) as compared to the Pre-Pandemic subgroup ( $M d n=28.83$; $U=400.5$, $\mathrm{z}=-2.17, \mathrm{p}=0.03$ ). 
Table 1. Mean ages and standard deviations of the subgroups, DERS results, Mann-Whitney U test differences of DERS total scores for Pre-pandemic and Pandemic subgroups. $(* \mathrm{p}<.05>* * \mathrm{p}<.01)$.

\begin{tabular}{|c|c|c|c|c|c|c|c|c|c|c|c|}
\hline Group & Grade & Subgroup & $\mathbf{N}$ & $\begin{array}{c}\text { Mean } \\
\text { age } \\
\text { (in } \\
\text { years) }\end{array}$ & SD & $\begin{array}{c}\text { Mean } \\
\text { DERS } \\
\text { total }\end{array}$ & SD & $\begin{array}{l}\text { Mean } \\
\text { Rank }\end{array}$ & $\begin{array}{c}\text { Sum } \\
\text { of } \\
\text { Ranks }\end{array}$ & $\mathbf{U}$ & $\mathbf{P}$ \\
\hline \multirow{4}{*}{$\begin{array}{c}\text { Grammar } \\
\text { School } \\
\text { Females }\end{array}$} & \multirow[b]{2}{*}{$9^{\text {th }}$} & $\begin{array}{l}\text { Pre- } \\
\text { Pandemic }\end{array}$ & 63 & 14.82 & 0.49 & 80.39 & 19.48 & 53.98 & 3401 & \multirow{2}{*}{1385} & \multirow{2}{*}{$0.01 *$} \\
\hline & & Pandemic & 59 & 15.16 & 0.35 & 90.76 & 24.18 & 69.53 & 4102 & & \\
\hline & \multirow[b]{2}{*}{$10^{\text {th }}$} & $\begin{array}{l}\text { Pre- } \\
\text { Pandemic }\end{array}$ & 58 & 15.76 & 0.43 & 83.58 & 22.12 & 56.54 & 3279 & \multirow{2}{*}{1505} & \multirow{2}{*}{0.85} \\
\hline & & Pandemic & 53 & 16.16 & 0.44 & 83.54 & 24.88 & 55.41 & 2936 & & \\
\hline \multirow{4}{*}{$\begin{array}{c}\text { Grammar } \\
\text { School } \\
\text { Males }\end{array}$} & \multirow[b]{2}{*}{$9^{\text {th }}$} & $\begin{array}{l}\text { Pre- } \\
\text { Pandemic }\end{array}$ & 22 & 14.94 & 0.65 & 80.00 & 14.61 & 39.00 & 858 & \multirow{2}{*}{561} & \multirow{2}{*}{0.79} \\
\hline & & Pandemic & 53 & 15.39 & 0.42 & 79.35 & 16.52 & 37.58 & 1992 & & \\
\hline & \multirow[b]{2}{*}{$10^{\text {th }}$} & $\begin{array}{l}\text { Pre- } \\
\text { Pandemic }\end{array}$ & 27 & 15.96 & 0.43 & 72.96 & 17.50 & 28.83 & 778 & \multirow{2}{*}{400} & \multirow{2}{*}{$0.03 *$} \\
\hline & & Pandemic & 43 & 16.55 & 0.45 & 84.41 & 23.07 & 39.69 & 1706 & & \\
\hline \multirow{2}{*}{$\begin{array}{c}\text { Vocational } \\
\text { School } \\
\text { Males }\end{array}$} & \multirow[b]{2}{*}{$9^{\text {th }}$} & $\begin{array}{l}\text { Pre- } \\
\text { Pandemic }\end{array}$ & 71 & 15.49 & 0.55 & 67.40 & 17.10 & 49.40 & 3507 & \multirow{2}{*}{951} & \multirow{2}{*}{$0.00 * *$} \\
\hline & & Pandemic & 58 & 15.47 & 0.45 & 89.41 & 25.50 & 84.09 & 4877 & & \\
\hline
\end{tabular}

Table 2. Means and standard deviations of chronological and bone age for the two male cohorts.

\begin{tabular}{|c|c|c|c|c|c|}
\hline Group & $\mathbf{N}$ & $\begin{array}{c}\text { Chron. age } \\
\text { (mean in y) }\end{array}$ & SD & $\begin{array}{c}\text { Bone age } \\
(\text { mean in y) }\end{array}$ & SD \\
\hline $\begin{array}{c}\text { Grammar } \\
\text { School Males } 9^{\text {th }} \\
\text { Grade }\end{array}$ & 31 & 15.33 & 0.46 & 15.50 & 1.49 \\
\hline $\begin{array}{c}\text { Vocational } \\
\text { School Males } 9^{\text {th }} \\
\text { Grade }\end{array}$ & 96 & 15.4 & 0.57 & 16.08 & 1.19 \\
\hline
\end{tabular}




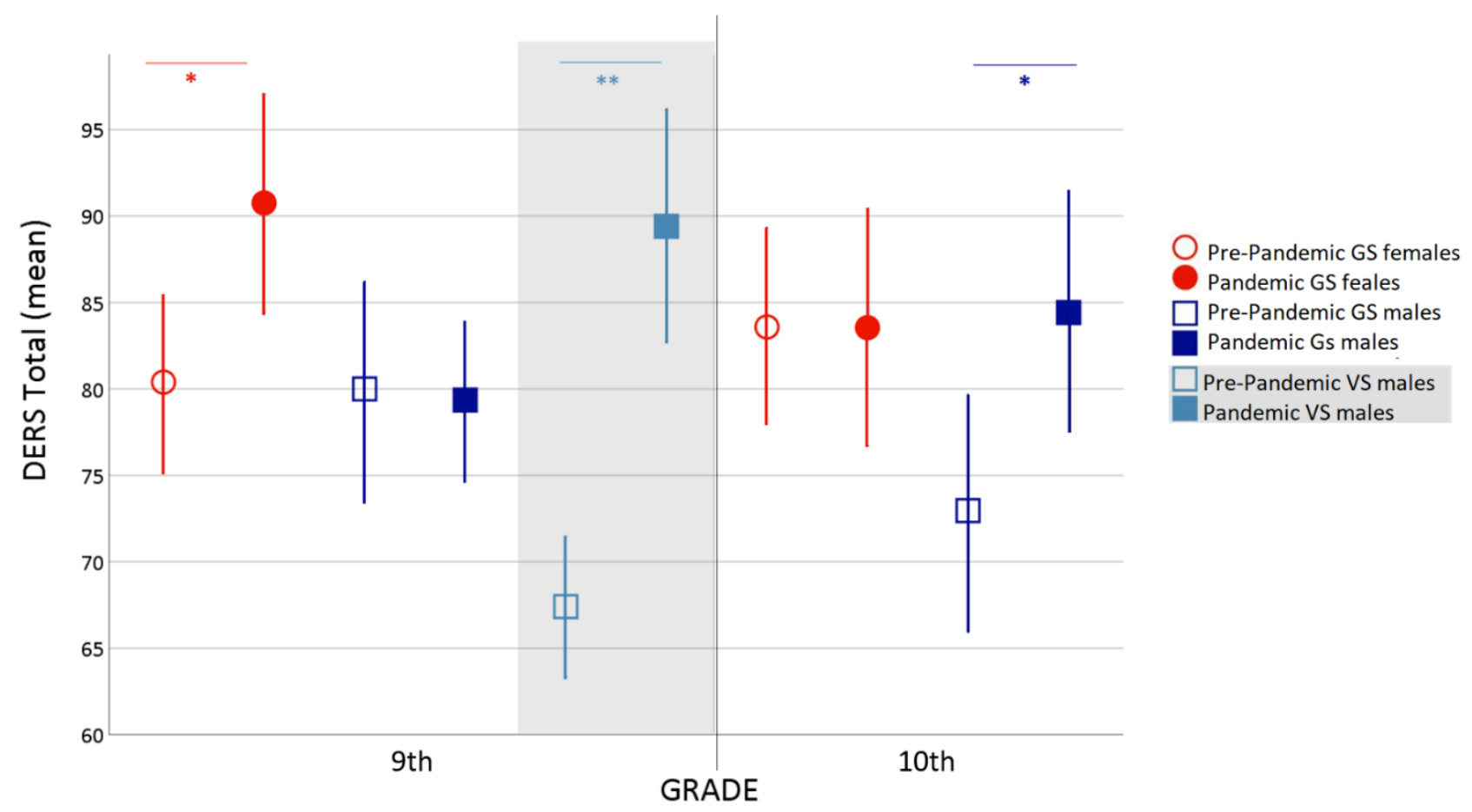

Figure 1. DERS total score means of the Pre-Pandemic (empty symbols) and Pandemic (solid symbols) subgroups. Error bars indicate $2 \mathrm{SE}$. The asterisk indicates a significant difference in the Mann-Whitney U test $(* \mathrm{p}<0.05$; ** $\mathrm{p}<0.01)$ In the Grammar School (GS) female cohort the 9th grader Pandemic subgroup has higher DERS Total scores as compared to Pre-Pandemic, while there is no difference between the two subgroups in $10^{\text {th }}$ grade. This pattern of difference was the reverse in the GS male cohort: there is no significant difference between the Pre-Pandemic and Pandemic subgroups in $9^{\text {th }}$ grade, whereas a significant difference occurred between the $10^{\text {th }}$ grader subgroups. The difference between the subgroups of the $9^{\text {th }}$ grader Vocational School males was similar to the $9^{\text {th }}$ grader GS female pattern: the Pandemic subgroup showed significantly higher DERS Total scores than the Pre-Pandemic.

Univariate analysis of variance (ANOVA) was carried out to compare the two groups on chronological and bone age variables. ANOVA revealed no difference between samples on chronological age $(\mathrm{F}(1,125)=0.38, \mathrm{p}=0.54)$, however, the Vocational School males' bone age (16.08y, $\mathrm{SD}=1.19)$ was significantly higher as compared to Grammar School males'(15.5y, $\mathrm{SD}=1.49 ; \mathrm{F}(1,125)=4.81, \mathrm{p}=0.03)$. We ran paired sample t-tests to determine whether chronological age and bone age diverge from each other within the two groups of males. We found no difference between the two variables in the population of GS males $(\mathrm{t}(30)=-.675, \mathrm{p}=.505)$, while an average 0.67 year (cc. 8 months) difference was shown in the VS males group regarding bone age $(\mathrm{t}(95)=-5.29 \mathrm{p}<.000)$. 


\section{Discussion}

According to our original purpose, we were able to assess the immediate impact of the current pandemic events on emotion regulation in adolescents. We found a gender difference in the timing of the strongest negative impact; females being affected about a year earlier than males. Interestingly, while emotion regulation (as assessed by the total score on DERS) in $9^{\text {th }}$ grader females of the Pandemic cohort seemed to be significantly above that of the Pre-Pandemic group (indicating more regulation problems), $10^{\text {th }}$ grader Pre-Pandemic females provided the same scores as those in the Pandemic group. males going to grammar school had the opposite pattern: $9^{\text {th }}$ graders were not affected by the Pandemic in emotion regulation according to their DERS scores, while those in the $10^{\text {th }}$ grade Pandemic group scored significantly above (indicating more emotion regulation problems) the Pre-Pandemic group. The one-year shift in results between females and males suggests a strong parallel to females 'earlier puberty maturation. Gender difference in the timing of puberty is an acknowledged fact, females typically outstrip males by one and a half years (for review see Steinberg \& Morris, 2001). This pattern of results, therefore, not only points to a gender difference in the timing of vulnerability but indicates a "window" of vulnerability in both genders: females being very sensitive to the stress due to the pandemic circumstances in the $9^{\text {th }}$ grade, and more stable after that; males being unaffected in the $9^{\text {th }}$ grade, and vulnerable a year later. For future studies, it would be interesting to see whether the $9^{\text {th }}$ grade window in females extends to earlier grades or whether it is a one-year vulnerability window indeed, and whether the $10^{\text {th }}$ grade window in males extends to later grades. However, we hope that the current pandemic will not provide the grounds for such an investigation because with the vaccinations the negative effects will subside soon.

We were also particularly interested in those potential windows of vulnerability that are suggested by the earlier mentioned brain maturational processes, e.g., cortical pruning and late frontolimbic maturation (Arain et al., 2013; Banks et al., 2007; Johnson et al., 2003) and neurotransmitter imbalance (Canli \& Lesch, 2007; Laviolette, 2007; Thayer \& Lane, 2000). To this end, we assessed the biological age of both grammar and vocational school adolescents assuming that biological age as assessed by bone age will be in correlation with brain maturation (Kovács et al., 2021). We found that vocational school students are significantly more mature than grammar school students, and, accordingly, these males also show an earlier window of vulnerability. The results corroborate our hypothesis with respect to the maturational effects in emotional regulation that should determine when a particular individual is most sensitive to stressful events. It seems that earlier maturing males, attending a vocational school, are closer in terms of emotional maturity to grammar school females than to grammar school males. This is a novel and very surprising finding as similar comparisons have not been made before.

Based on our findings, we would like to suggest a novel hypothesis with respect to vulnerability windows in emotional development that might have practical relevance for the teachers and 
caretakers of adolescents. As it is illustrated in Figure 2., we assume that, although by reaching adolescence, children have acquired differentiated and diversified emotion expression and regulation skills, the adolescent years also bring a great deal of changes before emotion regulation becomes adultlike. As in the case of any developmental event, these changes will reach the point of fastest change in between the levels of childlike and adultlike emotion regulation. Since we are not assuming stepwise development, a sigmoid function is a good approximation of that, and the inflection point of this curve characterises the point of fastest change (Burchinal \& Appelbaum, 1991). The main idea of our hypothesis is that around the point of fastest change, there is a window of heightened vulnerability as well (Charmandari et al., 2003; Larsen \& Luna, 2018; Semple et al., 2013). As we detailed in the introduction, emotion regulation is dependent on the maturation of brain structures and systems as well as on age, gender, and contextual factors. All these determining factors will define the actual developmental curve for each particular group of youth, described, e.g., by their chronological and biological age and gender. These curves, drawn hypothetically in Figure 2. For the three cohorts that we studied, very clearly show the relevance of a multifactorial view of development that is not simply dependent on chronological age.

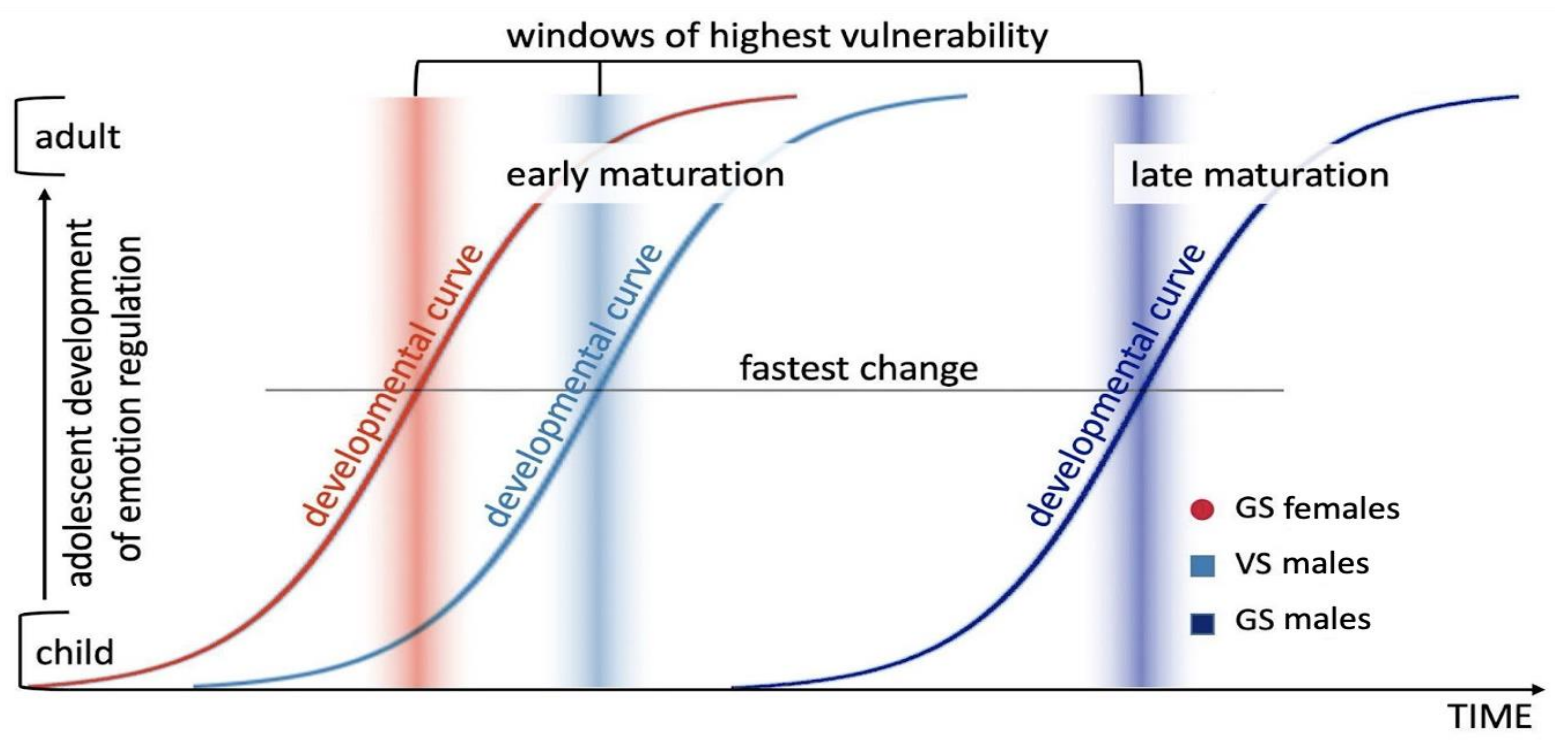

Figure 2. Schematic representation of the adolescent development of emotional regulation. The theoretical functions each represent the adolescent course of development between the end of childhood and adulthood. The fastest developmental change occurs at the inflection points of these curves. Assuming similar developmental speed (slope of the curve) in earlier and later maturing groups, the inflection points define the centers of windows of highest vulnerability where development and plasticity are fastest, and vulnerability is greatest. GS: grammar school, VS: vocational school.

The practical message of our results combined with the theoretical scenario described in Figure 2. is that adolescence is not simply a period of increased vulnerability in the emotional domain, but it is a fine-grained developmental process, with potentially narrow windows for heightened 
sensitivity and vulnerability. These windows seem to be timed very differently depending on age, maturity, gender, and other contextual factors. Our concrete results suggest that while grammar school females and vocational school males may need the most intensive attention and help in the 9th grade, grammar school males will need it a grade later. 


\section{References}

Arain, M., Haque, M., Johal, L., Mathur, P., Nel, W., Rais, A., Sandhu, R., \& Sharma, S. (2013). Maturation of the adolescent brain. Neuropsychiatric Disease and Treatment, 9, 449-461. PubMed. https://doi.org/10.2147/NDT.S39776

Banks, S. J., Eddy, K. T., Angstadt, M., Nathan, P. J., \& Phan, K. L. (2007). Amygdala-frontal connectivity during emotion regulation. Social Cognitive and Affective Neuroscience, 2(4), 303-312. https://doi.org/10.1093/scan/nsm029

Bunford, \& Evans, S. W. (2017). Emotion regulation and social functioning in adolescence: Conceptualization and treatment. In School Mental Health Services for Adolescents (1st ed., pp. 161-181). Oxford University Press. https://doi.org/10.1093/medpsych/9780199352517.003.0008

Bunford, N., Evans, S. W., Becker, S. P., \& Langberg, J. M. (2015). Attentiondeficit/hyperactivity disorder and social skills in youth: A moderated mediation model of emotion dysregulation and depression. Journal of Abnormal Child Psychology, 43(2), 283-296. PubMed. https://doi.org/10.1007/s10802-014-9909-2

Bunford, N., Evans, S. W., \& Langberg, J. M. (2018). Emotion Dysregulation Is Associated With Social Impairment Among Young Adolescents With ADHD. Journal of Attention Disorders, 22(1), 66-82. https://doi.org/10.1177/1087054714527793

Burchinal, M., \& Appelbaum, M. I. (1991). Estimating Individual Developmental Functions: Methods and Their Assumptions. Child Development, 62(1), 23-43. JSTOR. https://doi.org/10.2307/1130702

Canli, T., \& Lesch, K.-P. (2007). Long story short: The serotonin transporter in emotion regulation and social cognition. Nature Neuroscience, 10(9), 1103-1109. https://doi.org/10.1038/nn1964

Chaplin, T. M., \& Aldao, A. (2013). Gender differences in emotion expression in children: A meta-analytic review. Psychological Bulletin, 139(4), 735-765. PubMed. https://doi.org/10.1037/a0030737

Charmandari, E., Kino, T., Souvatzoglou, E., \& Chrousos, G. P. (2003). Pediatric Stress: Hormonal Mediators and Human Development. Hormone Research in Paediatrics, 59(4), 161-179. https://doi.org/10.1159/000069325

Derogatis, L. R., \& Melisaratos, N. (1983). The Brief Symptom Inventory: An introductory report. Psychological Medicine, 13(3), 595-605. Cambridge Core. https://doi.org/10.1017/S0033291700048017

Durkin, M. S., Khan, N., Davidson, L. L., Zaman, S. S., \& Stein, Z. A. (1993). The effects of a natural disaster on child behavior: Evidence for posttraumatic stress. American Journal of Public Health, 83(11), 1549-1553. https://doi.org/10.2105/AJPH.83.11.1549

Ellis, W. E., Dumas, T. M., \& Forbes, L. M. (2020). Physically isolated but socially connected: Psychological adjustment and stress among adolescents during the initial COVID-19 crisis. Canadian Journal of Behavioural Science / Revue Canadienne Des Sciences Du 
Comportement, 52(3), 177-187. https://doi.org/10.1037/cbs0000215

Farello, G., Altieri, C., Cutini, M., Pozzobon, G., \& Verrotti, A. (2019). Review of the Literature on Current Changes in the Timing of Pubertal Development and the Incomplete Forms of Early Puberty. Frontiers in Pediatrics, 7, 147. https://doi.org/10.3389/fped.2019.00147

Gratz, K. L., \& Roemer, L. (2004). Multidimensional Assessment of Emotion Regulation and Dysregulation: Development, Factor Structure, and Initial Validation of the Difficulties in Emotion Regulation Scale. Journal of Psychopathology and Behavioral Assessment, 26(1), 41-54. https://doi.org/10.1023/B:JOBA.0000007455.08539.94

Johnson, P. A., Hurley, R. A., Benkelfat, C., Herpertz, S. C., \& Taber, K. H. (2003).

Understanding Emotion Regulation in Borderline Personality Disorder: Contributions of Neuroimaging. The Journal of Neuropsychiatry and Clinical Neurosciences, 15(4), 397402. https://doi.org/10.1176/appi.neuropsych.15.4.397

Kinner, V. L., Het, S., \& Wolf, O. T. (2014). Emotion regulation: Exploring the impact of stress and sex. Frontiers in Behavioral Neuroscience, 8, 397.

https://doi.org/10.3389/fnbeh.2014.00397

Kökönyei, G., Urbán, R., Reinhardt, M., Józan, A., \& Demetrovics, Z. (2014). The difficulties in emotion regulation scale: Factor structure in chronic pain patients. Journal of Clinical Psychology, 70(6), 589-600. https://doi.org/10.1002/jclp.22036

Kovács, I., Kovács, K., Gerván, P., Utczás, K., Oláh, G., Tróznai, Z., Berencsi, A., Szakács, H., \& Gombos, F. (2021). Skeletal maturity predicts cognitive abilities in human adolescents. BioRxiv, 2021.05.02.442351. https://doi.org/10.1101/2021.05.02.442351

Langer, K., Hagedorn, B., Stock, L.-M., Otto, T., Wolf, O. T., \& Jentsch, V. L. (2020). Acute stress improves the effectivity of cognitive emotion regulation in men. Scientific Reports, 10(1), 11571. https://doi.org/10.1038/s41598-020-68137-5

Larsen, B., \& Luna, B. (2018). Adolescence as a neurobiological critical period for the development of higher-order cognition. Neuroscience \& Biobehavioral Reviews, 94, 179195. https://doi.org/10.1016/j.neubiorev.2018.09.005

Laviolette, S. R. (2007). Dopamine modulation of emotional processing in cortical and subcortical neural circuits: Evidence for a final common pathway in schizophrenia?

Schizophrenia Bulletin, 33(4), 971-981. PubMed. https://doi.org/10.1093/schbul/sbm048

Lee, J. (2020). Mental health effects of school closures during COVID-19. The Lancet Child \& Adolescent Health, 4(6), 421. https://doi.org/10.1016/S2352-4642(20)30109-7

Marsee, M. A. (2008). Reactive Aggression and Posttraumatic Stress in Adolescents Affected by Hurricane Katrina. Journal of Clinical Child \& Adolescent Psychology, 37(3), 519-529. https://doi.org/10.1080/15374410802148152

Muris, P., Schmidt, H., \& Merckelbach, H. (2000). Correlations among two self-report questionnaires for measuring DSM-defined anxiety disorder symptoms in children: The Screen for Child Anxiety Related Emotional Disorders and the Spence Children's Anxiety Scale. Personality and Individual Differences, 28(2), 333-346.

https://doi.org/10.1016/S0191-8869(99)00102-6

Neumann, A., van Lier, P. A. C., Gratz, K. L., \& Koot, H. M. (2010). Multidimensional 
Assessment of Emotion Regulation Difficulties in Adolescents Using the Difficulties in Emotion Regulation Scale. Assessment, 17(1), 138-149.

https://doi.org/10.1177/1073191109349579

Nolen-Hoeksema, S., Larson, J., \& Grayson, C. (1999). Explaining the gender difference in depressive symptoms. Journal of Personality and Social Psychology, 77(5), 1061-1072. https://doi.org/10.1037/0022-3514.77.5.1061

Qualtrics. (2021). Qualtrics (Version 2021) [Computer software]. Qualtrics. https://www.qualtrics.com

Raio, C. M., Orederu, T. A., Palazzolo, L., Shurick, A. A., \& Phelps, E. A. (2013). Cognitive emotion regulation fails the stress test. Proceedings of the National Academy of Sciences of the United States of America, 110(37), 15139-15144. PubMed. https://doi.org/10.1073/pnas.1305706110

Raio, C. M., \& Phelps, E. A. (2015). The influence of acute stress on the regulation of conditioned fear. Stress Resilience, 1, 134-146. https://doi.org/10.1016/j.ynstr.2014.11.004

Scott, B. G., Lapré, G. E., Marsee, M. A., \& Weems, C. F. (2013). Aggressive behavior and its associations with posttraumatic stress and academic achievement following a natural disaster. Journal of Clinical Child and Adolescent Psychology: The Official Journal for the Society of Clinical Child and Adolescent Psychology, American Psychological Association, Division 53, 43(1), 43-50. PRIME.

Semple, B. D., Blomgren, K., Gimlin, K., Ferriero, D. M., \& Noble-Haeusslein, L. J. (2013). Brain development in rodents and humans: Identifying benchmarks of maturation and vulnerability to injury across species. Progress in Neurobiology, 106-107, 1-16. https://doi.org/10.1016/j.pneurobio.2013.04.001

Steinberg, L., \& Morris, A. S. (2001). Adolescent Development. Annual Review of Psychology, 52(1), 83-110. https://doi.org/10.1146/annurev.psych.52.1.83

Thayer, J. F., \& Lane, R. D. (2000). A model of neurovisceral integration in emotion regulation and dysregulation. Arousal in Anxiety, 61(3), 201-216. https://doi.org/10.1016/S01650327(00)00338-4

Weinberg, A., \& Klonsky, E. D. (2009). Measurement of emotion dysregulation in adolescents. Psychological Assessment, 21(4), 616-621. https://doi.org/10.1037/a0016669

Zhou, S.-J., Zhang, L.-G., Wang, L.-L., Guo, Z.-C., Wang, J.-Q., Chen, J.-C., Liu, M., Chen, X., \& Chen, J.-X. (2020). Prevalence and socio-demographic correlates of psychological health problems in Chinese adolescents during the outbreak of COVID-19. European Child \& Adolescent Psychiatry, 29(6), 749-758. https://doi.org/10.1007/s00787-02001541-4

Zimmer-Gembeck, M. J., \& Skinner, E. A. (2011). Review: The development of coping across childhood and adolescence: An integrative review and critique of research. International Journal of Behavioral Development, 35(1), 1-17. https://doi.org/10.1177/0165025410384923 
